\title{
3D navigation in surgery of Eagle syndrome
}

\author{
Czako L ${ }^{1}$, Hirjak D ${ }^{1}$, Simko $\mathrm{K}^{1}$, Thurzo A ${ }^{2}$, Janovszky A ${ }^{3}$, Galis $\mathrm{B}^{1}$ \\ Departmentof of Oral and Maxillofacial Surgery of Medical Faculty of Comenius University \\ and University Hospital Bratislava, Bratislava, Slovakia. brano.galis@gmail.com
}

\begin{abstract}
INTRODUCTION: Eagle's syndrome is a rare condition caused by the elongation of the styloid process $(>4$ $\mathrm{cm}$ ) or calcification of the stylohyoid ligament. Patients with Eagle's syndrome typically present various clinical symptoms, such as headache, facial pain, neck pain, pulsating pain, sore throat, foreign body sensation, dysphagia, dysphonia, cough, voice changes, otalgia or vertigo. 3D printing refers to processes in which successive layers of material are formed from 3D computer tomography data to synthesize a three-dimensional object. This new diagnostic technique of rapid prototyping technology led to innovative new applications in biomedicine. OBJECTIVE: The primary goal for this case study was to find out, whether the nowadays so popular 3D technology aids in the treatment of the Eagle syndrome or other similar craniofacial abnormalities during the surgical procedure. CASE PRESENTATION: We report a case of a patient who initially presented a combination of symptoms like headache, sore throat, neck pain, which exacerbated with the movement of the head. This case report provides a brief review of the diagnosis and surgical management of the Eagle's syndrome with the help of 3D model navigation. CONCLUSION: Eagle's syndrome is difficult to diagnose due to its wide variability in symptoms. The inherent accuracy and other properties of 3D printing have allowed it to have exciting applications in anatomy education and surgery, with great benefit to the maxillofacial surgery. With the assistance of 3D technology, it is much easier for the surgeon to plan the surgical approach and the surgery, and significantly reduce the operation time (Fig. 3, Ref. 22). Text in PDF www.elis.sk.

KEY WORDS: Eagle syndrome, stylohyoidectomy, 3D assisted surgery, printed models, three dimensional navigation.
\end{abstract}

\section{Introduction}

Eagle's or stylohyoid syndrome is a generally unknown and rarely identified anatomical and clinical condition involving the head and region $(1,2)$. It is characterized by the symptoms of recurrent or permanent throat pain, pharyngeal foreign body sensation, dysphagia, bilateral otalgia, and neck pain $(3,4)$. Historically, stylohyoid pain syndromes have been delineated based upon their etiology, i.e. acquired versus congenital (5). Eagle syndrome proper has been described as a pain syndrome associated with an elongated styloid. The congenital variant, often described as stylohyoid syndrome has been described as a syndrome with pain and symptoms of carotid compression (syncope, presyncope, and even transient ischemic attacks) caused by an ossified stylohyoid ligament $(3,6)$. Eagle's syndrome has also been called: stylohyoid syndrome, styloid syndrome, elongated process syndrome, stylal-

${ }^{1}$ Departmentof of Oral and Maxillofacial Surgery of Medical Faculty of Comenius University and University Hospital Bratislava, Bratislava, Slovakia, ${ }^{2}$ Department of simulation and virtual medical education of Medical Faculty of Comenius University Bratislava, Bratislava, Slovakia, and ${ }^{3}$ Departmentof of Oral and Maxillofacial Surgery of Medical Faculty University of Szeged, Albert Szent-Györgyi Medical Center, Szeged, Hungary

Address for correspondence: B. Galis, MD, Department of Oral and Maxillofacial Surgery of Medical Faculty of Comenius University and University Hospital Bratislava, Ruzinovska 6, SK-826 06 Bratislava, Slovakia. Phone: +421 248234865 gia, styloid-stylohyoid syndrome, styloid dysphagia, chronic styloid angina, temporal rheumatic styloiditis, stylocarotid syndrome and the Garel-Bernfeld syndrome (4).

Incidences of abnormal stylohyoid length range from $4 \%$ to $28 \%(7,8)$. The incidence are higher if calcification of the stylohyoid complex is included 22-84\% $(9,10)$.

Eagle syndrome is an important clinical condition for the maxillofacial surgeons and otolaryngologist to recognize. This is due to the variety of clinical signs presentations, potentially serious complications, and the fact, that Eagle syndrome is often amenable to treatment. In this paper, we present the benefits and help of 3D model navigation in surgical treatment of Eagle/stylohyoid syndrome.

\section{Methods and case report}

For this study, we aimed to use 3D printed models in navigation during the surgical procedure and focused to identify the exact location of the resection of the styloid process (Fig. 1) without damaging the surrounding anatomical structures. To assess the fidelity of the 3D printed model, we inspected it from the lateral and bottom. The model was examined to determine whether specific anatomical structures were located correctly and was of the appropriate shape. All 3D printed models were scanned by CT with the same parameters as those of the original temporal bone and mandible. The window level and window width of all images 

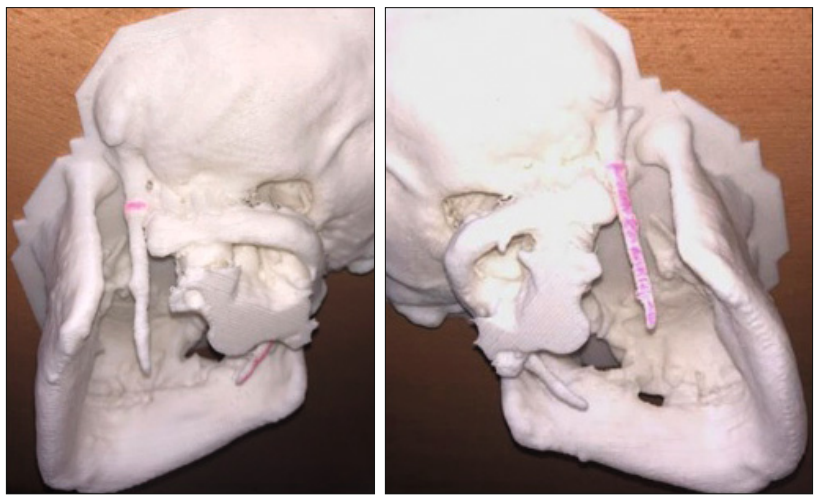

Fig. 1. The skull model fabricated by using 3-dimentional, (3D) printing technology reveals a bilateral elongated styloid processes.

were set at 1000 and $4000 \mathrm{HU}$, respectively. The reproducibility of structures such as position, length and form of styloid process, the location of stylomastoid foramen, transversal process of atlas and the distance from the ascendent ramus of mandible was evaluated by comparing CT images of the 3D models to those of the original. Subsequently we used this exact 3D model peroperatively as a spatial navigation during the surgery and exact resection of the styloid process.

The temporal bone models and the mandible models were printed from the PLY file on a full-color 3D printer (Projet 460 Plus, 3D Systems, Rock Hill, South Carolina, USA).. The printing materials consisted of plaster powder, which is fixed in place by a variety of colored binders. The model was left undisturbed for half a day to solidify firmly. Excess plaster powder was gently removed by air-blowing. These three-dimensional printing techniques represent a remarkable breakthrough in various fields. Among several techniques available for generating 3D models, the plaster powder bed and inkjet 3D printing method is thought to be the most suitable for creating the $3 \mathrm{D}$ models required for styloid process resection; this is because the reproduced texture is similar to bone and commercially available devices are easily accessible.

A 45-year old female presented to the clinic with a 3-year history of bilateral sided throat pain and pharyngeal foreign body sensation. The patient denied dysphagia, bilateral otalgia and other associated symptoms. The patient had tried several courses

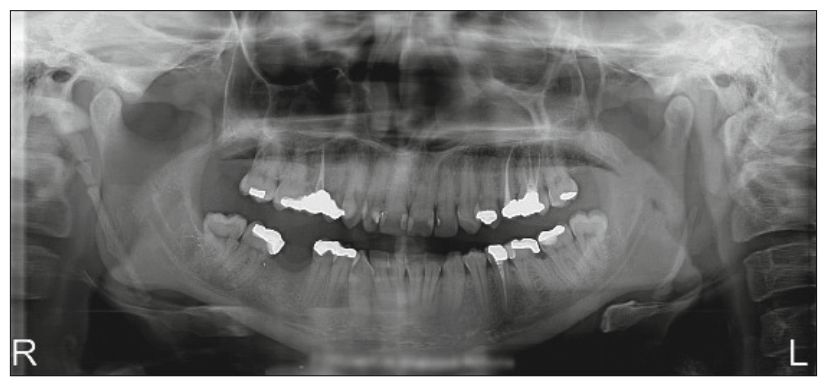

Fig. 2. Preoperative panoramic radiograph with an elongated styloid process bilaterally.

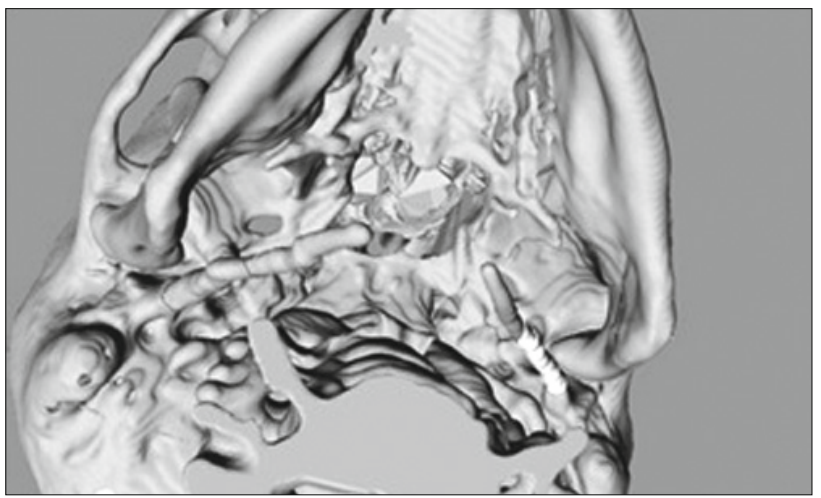

Fig. 3. 3-dimentional, (3D) computed tomography (CT) scan reveals bilateral elongated styloid processes (arrows).

of anti-inflammatory medication and multiple antibiotic therapies without sufficient effect. A complete head and neck examination including fiberoptic laryngoscopy was performed, and the only pertinent clinical finding was pain in the neck bilaterally with deep palpation and neck rotation. Intraoral palpation of the retromolar trigone and peritonsillar region also elicited pain. An OPG and subsequently computed tomography scan of the neck was obtained as displayed in Figures 2 and 3. Based on the radiographic analysis, the diagnosis of Eagle Syndrome was made. As the patient had failed multiple medical treatments, surgical intervention was offered and the patient was keen on pursuing this option. The patient underwent cervical/extraoral resection of the styloid process from retromandibular approach on the right side and submandibular approach on the left side with primary closure. Postoperatively she had an immediate resolution of symptoms following awakening in the recovery unit. She was discharged three days after surgery and had an uneventful post-operative course with only minimal pain medication requirements and quick resolution of regular oral intake.

\section{Discussion}

The symptoms of Eagle's syndrome are nonspecific and may mimic tumors, foreign bodies, infections, or neuralgia what make the correct diagnosis quite difficult based solely on clinical manifestations (11). These symptoms can be associated with the compression of the anatomic structures that are closely related to the styloid process and the stylohyoid ligament: facial, accessory, hypoglossal, vagal, and glossopharyngeal nerves, the internal jugular vein, and the internal carotid artery (12).

The styloid process is a cylindric bony outgrowth located immediately in front of the stylomastoid foramen and fused onto the inferior aspect of the temporal bone. The styloid process varies in length in different subjects as well as in individual patients. Radiographic studies have shown that a normal styloid process is generally varies from 2 to $3 \mathrm{~cm}$ in length $(8,13)$. Some other authors have considered a process to be elongated when greater than 4.0 $\mathrm{cm}$ in length, and the highest incidence of symptoms occurred over this length. An elongated styloid process is said to exist when either 
the styloid process alone or the combined lengths of the process and stylohyoid or stylomandibular ligaments exceed $40 \mathrm{~mm}$ (14).

Eagle's syndrome is a generally unknown and rarely identified anatomical and clinical condition involving the head and neck region. Despite the high incidence of abnormal length of stylohyoid process, the incidence of pain associated with these abnormalities is $4-10 \%$. While stylohyoid abnormalities often occur bilaterally, pain usually presents unilaterally (15).

Diagnosis is made both radiographically and by physical examination. Intraoral palpation of the styloid process in the tonsillar fossa is indicative of elongated styloid in that processes of normal length are not normally palpable. Extraoral palpation of the tip of the styloid should exacerbate existing symptoms. If highly suspicious for Eagle syndrome, confirmation can be made by radiographic studies (12).

The physical examination associated with a CT scan is the gold standard for the correct diagnosis and treatment of the Eagle's syndrome. In accordance with Piagkou et al., there are four different parameters for the diagnosis of Eagle's syndrome: (a) clinical manifestations, (b) digital palpation of the process in the tonsilar fossa, (c) radiological findings, and (d) lidocaine infiltration test (12). The lidocaine test is performed by an infiltration of $1 \mathrm{ml}$ of $2 \%$ lidocaine in the area where the styloid process is palpable in the tonsillar fossa. If the patient's symptoms and local sensitivity were reduced and with others positive results, Eagle's syndrome can be diagnosed (16).

The treatment for Eagle's syndrome can be pharmacologically, surgically, or both. Nonsurgical treatments include reassurance, nonsteroidal anti-inflammatory medications, and steroid injections $(17,18)$. The surgical management consists of two major procedures: the transoral approach or the extraoral-cervical approach $(18,19)$. The extraoral-cervical approach is safer and technically easier alternative that achieves an adequate treatment of Eagle's syndrome in cases if the styloid process is longer than $3.5-4 \mathrm{~cm}$ (18). The literature tends to support that surgical treatment results in more definitive treatment and long lasting symptomatic relief $(9,12,17,18,20)$.

An external, cervical approach provides the best exposure of styloid complex (18). This approach can be perform from submandibular or retromandibular incision $(9,12,18)$. One of the concerning risks of this extraoral approach is the potential for injury to the marginal mandibular branch of the facial nerve and internal jugular veins (21). Surgical treatment with help of 3D printed models can significantly reduce the risk of injury of these anatomical structures, give better help to decide, witch technique - intraoral or cervical - give better approach to the bone surface and where is possible most safely resect the styloid process (22). $3 \mathrm{D}$ model can be printed after preoperative diagnostic evaluation of this syndrome, is not expensive and lead to expedited, less invasive, more predictable surgery, with a significantly reduced operation time. Ultimately, various surgical techniques exist for the treatment of Eagle syndrome, each with its own merits and risks. Preoperative or peroperative using of 3D printed models can give safer surgery for all surgeons with better three - dimensional orientation.

\section{Conclusion}

Eagle syndrome is a rare clinical condition that can be associated with the elongation of the styloid process. It has a large variety of clinical presentations as evidenced by the multitude of nonspecific symptoms. As the result, it is important to understand the diagnostic workup, relevant imaging, and ultimate treatment options. With advances in medical management with 3D models and surgical approaches to the styloid process and complex, Eagle syndrome has become recognized more readily and has an established group of treatment options. 3D CT reconstruction and printing are beneficial in determining appropriate surgical strategy, and allowing the physician to better explain the lesion, and surgical details to patients.

Preoperative planning using 3D models illustrates to the patient and team the location of osteotomy cuts and provide a valuable training opportunities and reduce the surgical time.

\section{References}

1. Montalbetti L, Ferrandi D, Pergami P, Savoldi F. Elongated styloid process and Eagle's syndrome. Cephalalgia 1995: 80-93.

2. Eagle WW, Durham NC. Elongated styloid processes. Report of two cases. Arch Otolaryngol Head Neck Surg 1937; 25 (5): 584-587.

3. Colby CC, Del Gaudio JM. Stylohyoid Complex Syndrome. Arch Otolaryngol Neck Surg [Internet] 2011; 137 (3): 248. Available from: http:// archotol.jamanetwork.com/article.aspx?doi=10.1001/archoto.2011.25

4. Eagle WW. Elongated styloid process: Further observation and a new syndrome. Arch Otolaryngol - Head Neck Surg 1948; 47 (5): 630-640.

5. Morrison PJ, Morrison RJ, McKinstry CS. Familial ossification of the stylohyoid ligament in a three generation family - A new clinical entity displaying autosomal dominant inheritance. Br J Radiol 2012; 85 (1012): 458-489.

6. Farhat HI, Elhammady MS, Ziayee H, Aziz-Sultan MA, Heros RC. Eagle syndrome as a cause of transient ischemic attacks. J Neurosurg [Internet] 2009; 110 (1): 90-93. Available from: http://www.ncbi.nlm.nih. gov/pubmed/18821836

7. Eagle WW, Durham NC. Elongated Styloid Process: Symptoms and treatment. Arch Otolaryngol - Head Neck Surg 1958; 67 (2): 172-176.

8. Kaufman SM, Elzay RP, Irish EF. Styloid Process Variation: Radiologic and Clinical Study. Arch Otolaryngol 1970; 91 (5): 460-463.

9. Badhey A, Jategaonkar A, Anglin Kovacs AJ, Kadakia S, De Deyn PP, Ducic Y, et al. Eagle syndrome: A comprehensive review. Clin Neurol Neurosurg 2017; 34-38.

10. Ferrario VF, Sigurta D, Daddona A, Dalloca L, Miani A, Tafuro F, et al. Calcification of the stylohyoid ligament: Incidence and morphoquantitative evaluations. Oral Surg Oral Med Oral Pathol 1990; 69 (4): 524-529.

11. Blomgren K, Qvarnberg Y, Valtonen H. Spontaneous fracture of an ossified stylohyoid ligament. J Laryngol Otol 1999; 113 (9): 854-855.

12. Piagkou MN, Anagnostopoulou S, Kouladouros K, Piagkos G. Eagle's syndrome: A review of the literature. Clin Anat 2009; 22 (5): 545-558.

13. Monsour PAJ, Young WG, Barnes PB. Styloid-stylohyoid syndrome : a clinical update. Aust Dent J 1985; 30 (5): 341-345. 
14. Monsour PA, Young WG. Variability of the styloid process and stylohyoid ligament in panoramic radiographs. Oral Surgery, Oral Med Oral Pathol 1986; 61 (5): 522-526.

15. Correll RW, Jensen JL, Taylor JB, Rhyne RR. Mineralization of the stylohyoid stylomandibular ligament complex. Oral Surg Oral Med Oral Pathol [Internet] 1979; 48 (4): 286-291. Available from: http://www.embase.com/search/results?subaction=viewrecord \& from $=$ export\&id=L10204230\%0A http://dx.doi.org $/ 10.1016 / 0030-4220$ (79)90025-2

16. Prasad KC, Kamath MP, Reddy KJM, Raju K, Agarwal S. Elongated styloid process (Eagle's syndrome): A clinical study. J Oral Maxillofac Surg 2002; 60 (2): 171-175.

17. Slavin K V. Eagle syndrome: entrapment of the glossopharyngeal nerve? Case report and review of the literature. J Neurosurg 2002; 97 (1): 216-218.
18. Mayrink G, Figueiredo EP, Sato FRL, Moreira RWF. Cervicofacial pain associated with Eagle's syndrome misdiagnosed as trigeminal neuralgia. Oral Maxillofac Surg 2012; 16 (2): 207-210.

19. Matsumoto F, Kase K, Kasai M, Komatsu H, Okizaki T, Ikeda K. Endoscopy-assisted transoral resection of the styloid process in Eagle's syndrome. Case report. Head Face Med 2012; 8 (1): 2-5.

20. Mortellaro C, Biancucci P, Picciolo G, Vercellino V. Eagle's syndrome: Importance of A corrected diagnosis and adequate surgical treatment. J Craniofac Surg 2002; 13 (6): 755-758.

21. Fusco DJ, Asteraki S, Spetzl RF. Eagle's syndrome: Embryology, anatomy, and clinical management. Acta Neurochir (Wien) 2012; 154 (7): 1119-1126.

22. Lee DH, Yoon TM, Lee JK, Lim SC. The role of 3D-printing technology in the diagnosis of Eagle syndrome. Med (United States) 2018; 97 (13): 2017-2018.

Received February 23, 2019. Accepted May 15, 2019 